\title{
BMJ Open Quality care, public perception and quick-fix service management: a Delphi study on stressors of hospital doctors in Ireland
}

\author{
Blanaid Hayes, ${ }^{1,2}$ Deirdre Fitzgerald, ${ }^{3}$ Sally Doherty, ${ }^{4}$ Gillian Walsh ${ }^{5}$
}

To cite: Hayes B,

Fitzgerald D, Doherty S, et al.

Quality care, public

perception and quick-fix service management: a Delphi study on stressors of hospital doctors in Ireland. BMJ Open 2015;5:e009564. doi:10.1136/bmjopen-2015009564

- Prepublication history and additional material is available. To view please visit the journal (http://dx.doi.org/ 10.1136/bmjopen-2015009564).

Received 31 July 2015 Revised 28 September 2015 Accepted 16 October 2015

CrossMark

\footnotetext{
${ }^{1}$ Research Department, Royal College of Physicians of Ireland, Dublin 2, Ireland ${ }^{2}$ Occupational Health Department, Beaumont Hospital, Dublin 9, Ireland ${ }^{3}$ Medmark Occupational Healthcare, Cork, Ireland ${ }^{4}$ Division of Population and Health Sciences, Department of Psychology, Royal College of Surgeons in Ireland, Dublin 2, Ireland ${ }^{5}$ Research Department, Royal College of Physicians of Ireland, Dublin 2, Ireland
}

Correspondence to Dr Blanaid Hayes;

Blanaidmhayes@physicians.ie

\section{ABSTRACT}

Objectives: To identify and rank the most significant workplace stressors to which consultants and trainees are exposed within the publicly funded health sector in Ireland.

Design: Following a preliminary semistructured telephone interview, a Delphi technique with 3 rounds of reiterative questionnaires was used to obtain consensus. Conducted in Spring 2014, doctors were purposively selected by their college faculty or specialty training body.

Setting: Consultants and higher specialist trainees who were engaged at a collegiate level with their faculty or professional training body. All were employed in the Irish publicly funded health sector by the Health Services Executive.

Participants: 49 doctors: 30 consultants (13 male, 17 female) and 19 trainees (7 male, 12 female). Consultants and trainees were from a wide range of hospital specialties including anaesthetics, radiology and psychiatry.

Results: Consultants are most concerned with the quality of healthcare management and its impact on service. They are also concerned about the quality of care they provide. They feel undervalued within the negative sociocultural environment that they work. Trainees also feel undervalued with an uncertain future and they also perceive their sociocultural environment as negative. They echo concerns regarding the quality of care they provide. They struggle with the interface between career demands and personal life.

Conclusions: This Delphi study sought to explore the working life of doctors in Irish hospitals at a time when resources are scarce. It identified both common and distinct concerns regarding sources of stress for 2 groups of doctors. Its identification of key stressors should guide managers and clinicians towards solutions for improving the quality of patient care and the health of care providers.

\section{INTRODUCTION}

The working environment for hospital doctors in Ireland has undergone radical
Strengths and limitations of this study

- This study provides new information on the working lives of hospital consultants in Ireland and adds to previously published data on the working lives of specialty trainees at a time when resources are severely depleted.

- The high response rate among a wide range of specialties suggests that the topic was one of interest and importance to the participants, and that the Delphi method was attractive to them and allowed for in-depth exploration of the topic.

- The study draws attention to the links between workplace stress and health, and its identification of key stressors should guide managers and clinicians towards solutions for improving the quality of patient care and the health of care providers.

- A limitation of the study is that cohorts selected were likely to be highly engaged employees and their responses may not be applicable to hospital doctors in general.

change in recent years. ${ }^{1}$ Practice changes resulting in increased accountability, growing bureaucracy and the use of standardised evidence-based treatments which improve patient outcomes but erode physician autonomy are global phenomena. ${ }^{2}$ It is likely that unique local factors are also having an impact, not least of which was the implementation of the Medical Practitioners Act. ${ }^{3}$ This set out to enhance patient safety and professional accountability and it fundamentally altered how doctors would be treated by the regulator. Fitness to practice hearings are now held in public risking reputational damage even when no findings are made. A new offence of poor professional performance has been introduced and the Medical Council now has a lay majority.

There is evidence that hospital posts have become less attractive to both trainees and consultants. A recent review of basic 
specialist training (BST) in Ireland notes that the tensions between training requirements and service demands have contributed to the reported 'brain drain' of young doctors, with over half leaving to work abroad after graduation. ${ }^{4}$ Many of the graduates of Irish medical schools fail to return for higher specialist training here, despite having earlier indicated their aspiration to do so. ${ }^{5}$ Levels of distrust of the employer are high $^{6}$ and recruitment and retention of consultants has been challenged by a $30 \%$ pay reduction for new consultants introduced in October 2012. ${ }^{7}$ Many senior posts are vacant or are filled on a temporary basis impacting on the quality of patient care. ${ }^{8}$ This, when added to the stringent public service austerity measures of overall salary reductions and employment embargoes, has ensured that employment conditions for doctors are no longer attractive and has contributed to a national shortage at a time of a growing and ageing population and a greater burden of chronic diseases. ${ }^{9}$

Doctors are instrumental in delivering quality patient care. Resource shortages and their undermining of improved patient care programmes have contributed to low morale. ${ }^{10}$ There has been a breakdown in talks between the consultants' main representative association, the Irish Hospital Consultants Association (IHCA) and the employer, which has contributed to a lack of trust. ${ }^{10}$ In this environment, it is likely that stress levels in this group are high though there has been little research on sources of stress in the Irish consultant population. A recent study has analysed the experiences of junior hospital doctors who were unanimous in their conviction that workloads were too heavy with high numbers of patients along with staff shortages and little time to spend with patients or to attend to training needs. ${ }^{11}$ The Irish Medical Council's recently published survey Your Training Counts attests to the very variable quality of the training environment experienced by trainees and to levels of bullying and undermining behaviour which are double those reported by UK counterparts. ${ }^{12}$

Exposure to psychosocial risk factors at work has been shown to increase the risk of stress-related disorders and depression in workers generally. ${ }^{13} 14$

This study set out to identify the most significant workplace stressors to which hospital doctors in Ireland are exposed. Carried out in 2014, this qualitative study is the preliminary phase of a national quantitative study on health and well-being in this group. Though a wide range of standard instruments is available for measuring occupational psychosocial factors quantitatively, a qualitative method was favoured to enable a detailed description of diverse stressors to be identified including those which might pertain to the recent work challenges outlined above. ${ }^{15}$

The Delphi technique has been used in a variety of settings to establish consensus on a topic and to rank priorities. ${ }^{16}$ In this study, it allowed individual opinion on key workplace stressors for this geographically dispersed, working population to be transformed, through the multistage iterative methodology, into consensus. The 10 highest ranked items for each group were used in a national quantitative phase of the study.

\section{METHODS}

\section{Recruitment}

According to Delphi methodology, ${ }^{16}$ we consulted two groups of experts separately, that is, consultants and higher specialist trainees (HST) who were engaged at a collegiate level. They represent those currently practising in anaesthetics, emergency medicine, medicine, obstetrics/gynaecology, paediatrics, pathology, psychiatry, radiology and surgery within the Irish healthcare system.

Guidance was sought from the relevant professional bodies on how their representatives would be selected. In choosing consultants (trainers), doctors responsible for the overall training programmes in both higher specialist training and BST were approached. Trainees were chosen whose engagement was evident by their membership of working groups or their role as trainee representatives within their training body. The administrator of the relevant training body made direct contact with members. Where enrolment was inadequate, snowball sampling was used to augment the sample size or to address deficiencies in the sample mix.

Fifty-two consultants were contacted and 30 agreed to participate within the 2-month period allotted (table 1). All specialties were represented. Of the original 52, 33 were male and 19 were female, possibly reflecting the dominance of males at senior levels within training bodies. Respondents were more likely to be female and to be associated with Dublin teaching hospitals than with regional teaching hospitals.

For the HST recruitment process, 19 of 28 trainees contacted were available during the study timeframe (table 2). The sample represented all but two specialties. As with consultants, respondents were more likely to be female and were more likely to be associated with Dublin teaching hospitals.

Recruits were rewarded with certificates to be used by consultants to claim continuous professional development credits and by trainees to incorporate in their training portfolio. Respondents were invited to participate by email and were given detailed information on the process. They were asked to draw on their broad experience of working in the health system as well as their personal experience. Consent was received by reply email. Identities were anonymised for analysis and reporting.

\section{Delphi process}

As a precursor to the three-round Delphi process, a semistructured, confidential telephone interview was conducted incorporating six questions (table 3). Interviews were recorded on paper and transcribed for analysis. Following an introduction by the interviewer 
Table 1 Consultant recruitment to Delphi study

\begin{tabular}{|c|c|c|c|c|c|}
\hline Specialty & $\begin{array}{l}\text { Number registered with } \\
\text { professional body }\end{array}$ & $\begin{array}{l}\text { Total number } \\
\text { contacted }\end{array}$ & $\begin{array}{l}\text { Number } \\
\text { recruited }\end{array}$ & Male/female & Geographic area \\
\hline Anaesthetics & 243 & 11 & 3 & $1 / 2$ & $A=2, B=1$ \\
\hline Emergency medicine & 60 & 2 & 2 & $1 / 1$ & $A=2$ \\
\hline Medicine & 517 & 15 & 5 & $2 / 3$ & $A=3, B=2$ \\
\hline Obstetrics and gynaecology & 106 & 4 & 3 & $1 / 2$ & $A=2, B=1$ \\
\hline Paediatrics & 138 & 5 & 4 & $2 / 2$ & $A=3, B=1$ \\
\hline Pathology & 158 & 4 & 4 & $1 / 3$ & $A=2, B=2$ \\
\hline Psychiatry & 493 & 4 & 4 & $1 / 3$ & $A=1, B=2, C=1$ \\
\hline Radiology & 257 & 2 & 2 & $1 / 1$ & $A=1, B=1$ \\
\hline Surgery & 218 & 5 & 3 & $3 / 0$ & $A=3$ \\
\hline Total & 3582 & 52 & $30(58 \%)$ & $13 / 17$ & $A=19, B=10, C=1$ \\
\hline
\end{tabular}

A: denotes those working in a Dublin teaching hospital. B: denotes regional teaching hospital. C: denotes other.

where confidentiality was reiterated, each participant was asked to outline their own definition of stress. The respondents were then offered a definition from the Health and Safety Authority (HSA), to ensure that all had a clear understanding of what was meant by the term. The HSA defines stress as 'the negative reaction people have to aspects of their environment as they perceive it. Stress is therefore a response to a stimulus and involves a sense of inability to cope'. ${ }^{17}$ Question 4 (What are the key sources of work stress for doctors working in hospitals nowadays?) was the key component of the interview and responses formed the basis for the next stages of the study.

Responses to question 4 were analysed by both interviewers, and items were distilled from all responses into a list of individual statements. In order to ensure that the statements generated would be understood by participants, cognitive interviewing was used to test them. Consultants generated 50 statements while trainees generated 45 (see online supplementary appendices 1 and 2). Of these perceived stressors, a number were identified by both groups but a larger number was individual to each group.

The full list of stressors $(50 / 45)$ obtained through the interviews was distributed in random order by email to participants using an online survey instrument (http:// www.surveymonkey.com). From this list, respondents were asked to select the 10-25 most important stressors in round 1 . They were encouraged to add any new suggestions to their selection. Consultants identified 21 most popular stressors (as determined by the statistical mode) and this shortened list became the subject of the second round. No new stressors were added to the consultant list. Trainees identified 18 top stressors from the original list and added two new statements.

In round 2, respondents were asked to select the 10 most significant stressors from the list presented. The researchers selected the 10 most popular stressors collectively. These were circulated in round 3 .

Respondents were asked to rank the 10 stressors in order of importance using a five-level Likert scale strongly agree $(+2)$, agree $(+1)$, neutral (0) disagree $(-1)$ and strongly disagree $(-2)$. These responses were used to generate an arithmetic mean reflecting the importance of each item as a stressor with SD reflecting the spread of data and the degree of consensus. Any item scoring $>0$ was considered important.

In order to gain greater understanding of the broader themes behind these ranked items, an inductive exercise was undertaken in which the researchers coded each

Table 2 Trainee recruitment to Delphi study

\begin{tabular}{|c|c|c|c|c|c|}
\hline Specialty & $\begin{array}{l}\text { Number registered with } \\
\text { professional body }\end{array}$ & $\begin{array}{l}\text { Total number } \\
\text { contacted }\end{array}$ & $\begin{array}{l}\text { Number } \\
\text { recruited }\end{array}$ & Male/female & Geographic area \\
\hline Anaesthetics & 204 & 6 & 4 & $2 / 2$ & $A=2, B=2$ \\
\hline Medicine & 492 & 9 & 6 & $2 / 4$ & $A=3, B=2, C=1$ \\
\hline Obstetrics/gynaecology & 120 & 1 & 1 & $1 / 0$ & $A=1$ \\
\hline Paediatrics & 157 & 1 & 0 & NA & NA \\
\hline Radiology & 95 & 3 & 2 & $0 / 2$ & $A=1, C=1$ \\
\hline Surgery & 306 & 3 & 3 & $1 / 2$ & $A=3$ \\
\hline Total & 1833 & 28 & $19(68 \%)$ & $7 / 12$ & $A=13, B=4, C=2$ \\
\hline
\end{tabular}


Table 3 Framework of semistructured interview and responses

\begin{tabular}{|c|c|c|c|}
\hline Number & Question & $\begin{array}{l}\text { Consultant affirmative } \\
\text { responses: number (\%) }\end{array}$ & $\begin{array}{l}\text { Trainee affirmative } \\
\text { responses: number (\%) }\end{array}$ \\
\hline 1 & $\begin{array}{l}\text { Is stress an important concern for hospital consultants/ } \\
\text { trainees at the moment? }\end{array}$ & $30(100)$ & $19(100)$ \\
\hline \multirow[t]{5}{*}{2} & \multicolumn{3}{|c|}{ Which of the following best describes your view of the significance/extent of the problem } \\
\hline & - Not significant & 0 & 0 \\
\hline & - Somewhat significant & $2(7)$ & $1(5)$ \\
\hline & - Very significant & $13(43)$ & $7(37)$ \\
\hline & - Highly significant & $15(50)$ & $11(58)$ \\
\hline 3 & $\begin{array}{l}\text { Do you think work stress constitutes a significant } \\
\text { component of hospital doctors' overall stress? }\end{array}$ & See text & See text \\
\hline 4 & $\begin{array}{l}\text { What are the key sources of work stress for doctors working } \\
\text { in hospitals nowadays? }\end{array}$ & See text & See text \\
\hline 5 & $\begin{array}{l}\text { Do you think work-life balance is important in mitigating any } \\
\text { stress caused by work? }\end{array}$ & $23(77)$ & $16(84)$ \\
\hline 6 & Do you have anything further to add? & See text & See text \\
\hline
\end{tabular}

item into broader categories to facilitate categorisation and communication of results.

The top 10 stressors identified in this Delphi study were included in a separate quantitative study which yielded responses from over 1800 hospital doctors who were asked to rate them on a Likert scale.

\section{RESULTS}

Engagement with the process was good. Twenty-six $(87 \%)$ consultants responded in round 1, $24(80 \%)$ in round 2 and $26(87 \%)$ in round 3 . Sixteen $(84 \%)$ trainees responded in round $1,14(74 \%)$ in round 2 and $16(84 \%)$ in round 3.

During interview, 28 (93\%) consultants considered stress a very significant or highly significant problem as did $18(95 \%)$ trainees. Twenty-three $(77 \%)$ consultants considered work-life balance to be important in mitigating work stress and the others made comments such as 'we don't have it', 'all has been sacrificed on the altar of medicine', and 'it's important to get a break from colleagues moaning'. The majority of trainees (16 (84\%)) agreed and those who did not opined that it is impossible to achieve' or that 'for some it's not important as work success can mitigate stress'.

\section{Consultant stressors}

The top 10 stressors agreed by consultants were ranked and a weighted average was calculated which reflected the degree to which respondents affirmed or rejected each statement (scale $0-2$ ). All but 1 of these 10 statements were ranked in the top 10 in round 1 , suggesting that stressors identified as significant in the first round were seen as consistently important through sequential rounds. However, their relative importance was influenced by peer feedback during the process (table 4).

The most significant stressor experienced by consultants in Irish hospitals is the lack of long-term planning resulting in a service that is always reactive. Other highly ranked concerns relating to healthcare management were perceived 'quick fix' decisions and lack of good management leadership (\#1, 2, 8). Responses suggest that consultants are also deeply concerned about the quality of care being provided for patients. Four of their 10 highest ranked stressors relate to this theme. They are aware that good treatment takes time and that this is not available, citing staff shortages, poor facilities, inadequate time for important paper work and excessive patient numbers $(\# 3,5,7,10)$. There is evidence that they feel undervalued and sense a threat to their professional identity from their employer, the media and the regulator $(\# 4,6)$. This is exacerbated by unrealistic patient expectations $(\# 9)$.

\section{Trainee stressors}

The top 10 stressors agreed by trainees were similarly ranked. Of these, eight which were identified in round 1 appeared consistently through to round 3 . As for consultants, their relative importance was altered in sequential rounds, suggesting openness to influence by peers and a move towards the consensus for which the Delphi process is valued.

Trainees too feel undervalued and this is reflected in several statements including three of their top four stressors $(\# 1,3,4,7,10)$. They are concerned about recent revisions to the consultant contract, overall financial loss and an unattractive future. They share their trainers' concerns regarding the negative sociocultural environment in which they work with negativity being perceived to emanate from their employer and the media as well as the often unrealistic expectations of patients. They too are concerned by the quality of care they can provide citing shortage of doctors, nurses and allied health professionals $(\# 2,8,9)$. The relative underresourcing of the European Working Time Directive (EWTD) also has an adverse impact. There is evidence that they struggle with the interface between career demands and personal life. This is exemplified by 2 of 
Table 4 Ten most significant consultant stressors (in $\mathrm{RO}$ )

\begin{tabular}{|c|c|c|c|c|c|c|c|}
\hline Number & Stressors & $\begin{array}{l}\text { Round } 1 \\
\text { Per cent } \\
\text { respondents } \\
\text { (number of } \\
\text { respondents) }\end{array}$ & RO & $\begin{array}{l}\text { Round } 2 \\
\text { Per cent } \\
\text { respondents } \\
\text { (number of } \\
\text { respondents) }\end{array}$ & Ro & $\begin{array}{l}\text { Round } 3 \\
\text { Weighted } \\
\text { average } \\
(0-2)\end{array}$ & Ro \\
\hline 1 & $\begin{array}{l}\text { The lack of long-term planning means that the } \\
\text { service is always reactive }\end{array}$ & $54(14)$ & 10 & $58(14)$ & 5 & 1.6 & 1 \\
\hline 2 & $\begin{array}{l}\text { Decisions taken by management are often 'quick } \\
\text { fix' and driven by standards imposed externally, (eg, } \\
\text { HIQA, accreditation, appointing consultants without } \\
\text { supportive resources) while ignoring unique local or } \\
\text { clinical concerns }\end{array}$ & 77 (20) & 1 & $54(13)$ & 7 & 1.44 & 2 \\
\hline 3 & $\begin{array}{l}\text { The shortage of NCHDs and/or consultants impacts } \\
\text { on our ability to deliver safe care }\end{array}$ & 65 (17) & 5 & $58(14)$ & 5 & 1.44 & 2 \\
\hline 4 & $\begin{array}{l}\text { The contribution of doctors is perceived as having } \\
\text { been devalued by commentary from both the HSE } \\
\text { and the media and in recent years has contributed } \\
\text { to a negative working environment and lack of trust }\end{array}$ & 77 (20) & 1 & 79 (19) & 1 & 1.44 & 2 \\
\hline 5 & $\begin{array}{l}\text { The facilities and infrastructure are inadequate to } \\
\text { provide appropriate clinical care while respecting } \\
\text { the patient's dignity }\end{array}$ & $50(13)$ & 16 & $63(15)$ & 3 & 1.36 & 5 \\
\hline 6 & $\begin{array}{l}\text { The threat of complaints (and/or litigation) is a } \\
\text { backdrop to daily practice exacerbated by the } \\
\text { Medical Council's hostility to the profession }\end{array}$ & 77 (20) & 1 & 75 (18) & 2 & 1.32 & 6 \\
\hline 7 & $\begin{array}{l}\text { There is inadequate time to accomplish the } \\
\text { important paper work required to support safe } \\
\text { clinical care (eg, screening referrals, checking } \\
\text { results, reviewing letters) }\end{array}$ & $54(14)$ & 10 & $50(12)$ & 8 & 1.32 & 6 \\
\hline 8 & $\begin{array}{l}\text { There is a lack of good management leadership } \\
\text { which truly understands the complex demands and } \\
\text { responsibilities of the clinician's role }\end{array}$ & 69 (18) & 4 & $50(12)$ & 9 & 1.28 & 8 \\
\hline 9 & $\begin{array}{l}\text { Expectations of patients (and/or of their families) } \\
\text { have increased and are sometimes unrealistic. This } \\
\text { includes a sense of entitlement, often to procedures } \\
\text { or investigations which might be available in the } \\
\text { private sector but are not necessarily appropriate } \\
\text { according to best practice }\end{array}$ & $62(16)$ & 6 & $50(12)$ & 10 & 1.28 & 8 \\
\hline 10 & $\begin{array}{l}\text { The number of patients to be treated exceeds } \\
\text { international norms }\end{array}$ & $62(16)$ & 6 & $63(15)$ & 3 & 1.18 & 10 \\
\hline
\end{tabular}

their top 10 statements which relate to personal relationships, planning a family and the disruption caused by frequent moves $(\# 5,6)$.

\section{DISCUSSION}

This Delphi study sought to identify key workplace stressors for hospital doctors in Ireland at a time of national doctor shortage and great economic challenge. It is likely that stress in doctors impacts negatively on the delivery of high quality care. ${ }^{18}$ Much of the research on external sources of stress in the profession has been quantitative with use of validated tools identifying those stressors which are well recognised as risks, for example, long hours, sleep deprivation, high workloads, high demand, low support. ${ }^{2}$ We were keen to explore some unique aspects of medical working life which would not be identified through the administration of a standard 'tool' (eg, the management standards Indicator Tool). ${ }^{19}$ This study has provided insight into specific stressors within the current Irish context which would not usually be measured in quantitative studies.

Through the multi-iterative Delphi process, each group has reached a consensus on what are their key stressors and these have been ranked (tables 4 and 5).

Over $90 \%$ of consultants and trainees interviewed consider work stress to be a very significant or highly significant problem. Consultants are aware of their role within a complex organisational system and of the role and quality of healthcare management within that. This study suggests that their greatest concern is lack of longterm planning. They identified this as an important stressor with growing consensus as to its importance through the Delphi iterative process. Other concerns 
Table 5 Ten most significant trainee stressors (in RO)

\begin{tabular}{|c|c|c|c|c|c|c|c|}
\hline Number\# & & $\begin{array}{l}\text { Round } 1 \\
\text { Per cent } \\
\text { respondents } \\
\text { (number of } \\
\text { respondents) }\end{array}$ & RO & $\begin{array}{l}\text { Round } 2 \\
\text { Per cent } \\
\text { respondents } \\
\text { (number of } \\
\text { respondents) }\end{array}$ & RO & $\begin{array}{l}\text { Round } 3 \\
\text { Weighted } \\
\text { average } \\
(0-2)\end{array}$ & RO \\
\hline 1 & $\begin{array}{l}\text { The revision to the consultant contract with its } \\
\text { attenuated terms and conditions has devalued the } \\
\text { role of consultant contributing to low morale }\end{array}$ & 56 & 8 & $86(12)$ & 1 & 1.75 & 1 \\
\hline 2 & $\begin{array}{l}\text { The shortage of NCHDs and/or consultants and } \\
\text { the limited depth of choice at this time of general } \\
\text { shortage impacts on our ability to deliver safe care }\end{array}$ & 69 & 4 & $71(10)$ & 4 & 1.75 & 1 \\
\hline 3 & $\begin{array}{l}\text { There is financial stress attributable to reduction in } \\
\text { income, loss of overtime payments and significant } \\
\text { reduction in the education grant }\end{array}$ & 69 & 4 & 79 (11) & 2 & 1.69 & 3 \\
\hline 4 & $\begin{array}{l}\text { The consultant package is no longer attractive } \\
\text { enough to well-trained specialists, is potentially } \\
\text { divisive within departments and also restricts the } \\
\text { mobility of those currently in posts }\end{array}$ & 88 & 1 & $71(10)$ & 4 & 1.69 & 3 \\
\hline 5 & $\begin{array}{l}\text { Relationship commitments and/or planning a } \\
\text { family are surrendered to career demands }\end{array}$ & 88 & 1 & $71(10)$ & 4 & 1.63 & 5 \\
\hline 6 & $\begin{array}{l}\text { Having to move workplace (and accommodation) } \\
\text { frequently is disruptive, particularly to one's } \\
\text { personal life. This can occur at short notice }\end{array}$ & 63 & 7 & 79 (11) & 2 & 1.56 & 6 \\
\hline 7 & $\begin{array}{l}\text { The contribution of doctors is perceived as having } \\
\text { been devalued by commentary from both the HSE } \\
\text { and the media and in recent years has contributed } \\
\text { to a negative working environment and lack of } \\
\text { trust }\end{array}$ & 50 & 13 & $64(9)$ & 7 & 1.5 & 7 \\
\hline 8 & $\begin{array}{l}\text { The shortage of nurses and/or AHPs and/or } \\
\text { administrative staff (some of whom are now less } \\
\text { experienced than the demands of the job require) } \\
\text { impacts on our ability to deliver safe care }\end{array}$ & 50 & 13 & $57(8)$ & 8 & 1.5 & 7 \\
\hline 9 & $\begin{array}{l}\text { Though the EWTD is welcome in principle, the } \\
\text { necessary resources have not been provided to } \\
\text { ensure continuity of care (eg, doctors who are } \\
\text { familiar with the patients are not available for ward } \\
\text { rounds) }\end{array}$ & 56 & 8 & $57(8)$ & 8 & 1.38 & 9 \\
\hline 10 & $\begin{array}{l}\text { Expectations of patients (and/or of their families) } \\
\text { have increased and are sometimes unrealistic. }\end{array}$ & 56 & 8 & $57(8)$ & 8 & 1.13 & 10 \\
\hline
\end{tabular}

relating to management performance vis-à-vis quick fix decisions and lack of leadership were also identified as key stressors in early rounds suggesting that further rounds would not have changed the consensus that these are important stressors. A quote serves to illustrate:

You are responsible and accountable for things over which you have no control.

They feel insecure within the system of which they are part and powerless to influence what matters to them. This is an important finding as lack of control is well recognised as a predictor of workplace stress. Karasek's ${ }^{20}$ job-strain model of work stress encompasses job demand and control and he theorised that control buffered the negative effects of demand, reducing strain. Control in this context refers to the exercise of control over one's activities and skill usage. ${ }^{21}$ There is now strong evidence showing a causal association between 'high strain' jobs and common mental disorders. ${ }^{22}$ Further work by Theorell and Karasek $^{23}$ identified the mitigation provided by workplace support. This demand-controlsupport (DCS) model is perhaps the most influential model of stress in the workplace today. ${ }^{24}$ It focuses entirely on extrinsic aspects of the psychosocial work environment and not on the individual. Our study concerns a group of highly skilled employees who work long hours at high intensity whose key stressor reflects lack of control. This important finding adds to previous observations and may fuel further discussion about the tensions between clinician autonomy and the need to curtail costs. ${ }^{25}$ 
By contrast, trainee responses suggest that they are unaware of the role and responsibility of management though they can access management and leadership courses during their training. It seems they have little experience of this aspect of practice being preoccupied with front-line service delivery, training demands and career progression. Trainees are most concerned with threats to their professional identity. They feel undervalued in their role citing recent contractual and salary changes as major stressors. They perceive their employer and the media as having contributed to a negative working environment and lack of trust. Some direct comments highlight their lack of connectedness to the organisation in which they work:

Doctors are seen as passing through so there's no interest and we are not valued.

Specialist registrars always did long hours but they were well paid and this took the sting out of it and you were more likely to 'suck it up'. Now we are undervalued by the HSE and the public.

It all starts with HR. If they are welcoming, that sets things up positively.

They also believe there is little support for them if they are unwell as illustrated by:

There is pressure not to appear sick even if you have a problem as ultimately it will narrow your career options.

Consultants share this feeling of being undervalued and unsupported though they seem less affected by its financial manifestations than their junior colleagues. Though contractual and salary changes are clearly seen as stressors, they do not feature in the top 10. This belies the popular portrayal of consultants as 'greedy'. ${ }^{26}$ The perceived devaluation of their contribution attributed to the employer and the media is a highly ranked stressor as evidenced by its top ranking in rounds 1 and 2 yielding to joint second place in the final round. The negative working environment and lack of trust identified is likely to have a significant impact on well-being and is exacerbated by perceived hostility by the regulator and unrealistic societal expectations:

We are not looking for adulation, just appreciation for what we do.

The public perception is not that consultants work crazy long hours.

People feel they could be reported (to the regulator) for anything.

There is much evidence to support the positive role of occupational social support in mitigating stress. Within the DCS model, this usually refers to peer and supervisor support, particularly the latter which is not exactly what is emerging from this qualitative study. ${ }^{22}$ For a deeper understanding of the significance of this finding and its potential links with stress, one needs to look at a model which incorporates both intrinsic and extrinsic components of the psychosocial work environment. ${ }^{21}$ Siegrist's $^{27}$ effort-reward imbalance (ERI) model theorises that a lack of reciprocity between high effort and low reward leads to strain and that this is exacerbated by overcommitment. High ERI is strongly associated with an increased risk of mental health disorders. ${ }^{21}$ Reward encompasses three areas: money, esteem and career opportunities, including job security. ${ }^{21}$ Experience of ERI is frequent in the service professions and our study identifies this perceived lack of esteem by the employer and the media (arguably the voice of society) as being a significant occupational stressor for both consultants and trainees. Within the ERI model, overcommitment is a personality trait characterised as a pattern of coping with demand in combination with a strong desire for approval and esteem. ${ }^{21}$ While this trait is likely to be common in our study population, our focus was on external stressors and not on personality traits. ${ }^{28}$

Another concern for consultants is the quality of care being provided for patients. Some direct quotes serve to illustrate their concerns:

We are being pushed to see patients in shorter times than best practice would suggest.

There is not enough time to communicate with those who are less sick so they get more stressed.

They are also aware of the inadequacy of existing resources, both human and infrastructural:

The ridiculous workload and lack of staffing mean you can't progress and develop the service.

When you try to have difficult conversations with patients in an inappropriate environment (e.g. trolley) their confidence is undermined and this colours how they view adverse outcomes.

Trainees too are concerned about quality of care and list three such items in their top 10 stressors. One senses the intensity of the demand and the lack of down time in the following observations:

There are so many patients coming through and we are battling against delays so that their diseases don't progress.

We are not afraid of hard work but the daily demand is such that you don't even get to avail of simple human needs like lunch or the bathroom because of staff shortages.

They are experiencing the impact of the recent moves to implement the EWTD, an endeavour which is recognised to be challenging. ${ }^{29}$ Their concerns about the 
manner of its implementation highlight a great awareness of the risks to patient safety:

There is huge management pressure to comply with EWTD. This means having to put in the appearance that working times are confined but there are no safety mechanisms in place (e.g. safe hand-over period).

Finally, the trainee role is inherently conflicted with both service and training demands to be managed. The time commitment required to deliver on both, notwithstanding the EWTD, is considerable and the nature of the work, with demands that are unpredictable at times, and the requirement to move workplace frequently can interfere significantly with social and personal life. These are articulated as highly ranked stressors and any effort to be made in addressing them will require the close cooperation of the training bodies and the employer.

This study used a Delphi approach to explore the working life of doctors in Irish hospitals, an area which has not been well researched. Though viewed as a qualitative tool, the Delphi affords the opportunity for some quantitative analysis through use of the Likert scale in determining ranking allocation. As well as identifying key stressors, this study drew conclusions, through an inductive process, on what is the overall meaning of the findings which may help to identify solutions and appropriate supports. While the sample size of each cohort studied met the necessary criteria for the Delphi approach, the number of trainees interviewed was less than hoped and relatively few males contributed which may have biased the responses. However, there was representation from a variety of hospital types, good geographical spread and a wide range of specialties. The high response rates suggested an enthusiasm for the process and the subject.

Another possible limitation is that this group is comprised of consultants and trainees who are likely to be highly engaged employees. Though asked to consider the research question from their general rather than their personal experience, their responses may be biased to the latter and may not be applicable to doctors in general, for example, a less engaged doctor might well prioritise more immediate or personal priorities. The degree to which these doctors reflect the true concerns of their peers will be explored when the quantitative data are analysed.

This study provides new information on the working lives of consultants and adds to previously published data on the working lives of trainees. ${ }^{11}$ Both groups consider that the care they provide for patients is challenged by inadequate human and infrastructural resources. Both feel undervalued. Consultants view the regulator as unsupportive while trainees are quite preoccupied by financial concerns and poor future prospects. This is unsurprising given the well-documented removal of the training grant ${ }^{5}$ and the fact that many young doctors have incurred significant debts during training which they struggle to pay-off. ${ }^{30}$

This study draws attention to the links between workplace stress and health. It provides a voice for a group of professionals whose experience of their work environment matters. Its identification of key stressors should guide managers and clinicians towards solutions for improving the quality of patient care and the health of care providers. Some solutions will require both capital and human resources investment, for example, improved infrastructure, further recruitment. Others require a change in the culture of how healthcare is managed and in how hospital doctors are valued. All will require leadership and commitment. This in turn will influence how the media portrays the profession and how it is viewed by the public.

One unanswered question is whether the poor view of the quality of management is a true reflection of the performance of managers or representative of poor understanding among consultants of the demands and constraints under which managers operate. This question is hard to answer within an environment where performance management is in its infancy ${ }^{31}$ and where the perception when things go wrong is that fault lies with the clinician notwithstanding the evidence that with the inevitability of human error, adverse events are best prevented by addressing latent system failures. ${ }^{32}$ An exploration of how healthcare managers view their particular stressors might provide a useful comparison. The perception of clinical directors might also be explored, as they are doctors in management roles, expected to straddle the chasm between the demands of patient care and society's need to control costs. Such work would undoubtedly create a bridge for more collaborative engagement between senior doctors and managers.

In conclusion, this group of hospital doctors who may be considered to be exemplars and experts within their respective peer group believe that workplace stress for doctors is an issue of great concern. Both consultants and trainees are concerned about issues impacting on the quality of care they can provide to patients and they feel undervalued within their work organisation and beyond. Consultants are very concerned about the quality of healthcare management, while trainees struggle with the impact of training and service delivery on their personal lives.

Acknowledgements The authors greatly acknowledge the support of the members of Royal College of Physicians of Ireland's Research Department and for the use of its facilities. They are grateful for the contribution of all of the training bodies (Royal College of Physicians of Ireland, Royal College of Surgeons in Ireland including Irish Association of Emergency Medicine and Faculty of Radiology, College of Anaesthetists of Ireland, College of Psychiatrists of Ireland) who contributed to the study's Steering Group and who facilitated access to their members. Finally, they appreciate in particular the engagement of the participants who gave of their time so generously.

Contributors All authors met at least one of the criteria recommended by the ICMJE and have agreed on the final version of the manuscript. BH and GW were involved in conceiving and designing the original protocol. $\mathrm{BH}$ and $\mathrm{DF}$ designed and conducted the interviews. $\mathrm{BH}$ wrote the first draft of the manuscript. SD and others contributed to subsequent drafts. 
Funding We gratefully acknowledge the support of the Royal College of Physicians of Ireland, Royal College of Surgeons in Ireland and the College of Anaesthetists of Ireland who provided funding for the publication and dissemination of this study's findings.

Competing interests None declared.

Ethics approval Research Ethics Committee Royal College of Physicians of Ireland December 2013 (RCPI RECSAF 20).

Provenance and peer review Not commissioned; externally peer reviewed.

Data sharing statement No additional data are available.

Open Access This is an Open Access article distributed in accordance with the Creative Commons Attribution Non Commercial (CC BY-NC 4.0) license, which permits others to distribute, remix, adapt, build upon this work noncommercially, and license their derivative works on different terms, provided the original work is properly cited and the use is non-commercial. See: http:// creativecommons.org/licenses/by-nc/4.0/

\section{REFERENCES}

1. Thomas S, Burke S, Barry S. The Irish health-care system and austerity: sharing the pain. Lancet 2014;383:1545-6.

2. Arnetz BB. Psychosocial challenges facing physicians of today. Soc Sci Med 2001:52:203-13.

3. Oireachtas. Medical Practitioner's Act 2007. Ireland 2007.

4. Imrie K. Training 21st century clinical leaders: review of basic specialist training. Dublin: RCPI, 2014.

5. Bennett $\mathrm{D}$, Dornan T, Bergin $\mathrm{C}$, et al. Postgraduate training in Ireland: expectations and experience. Ir J Med Sci 2014;183: 611-20.

6. Culliton G. Dealing with our demoralised NCHDs. Irish Medical Times 2010 October 19.

7. Gantly D. Plugging the brain drain of our consultants. Irish Medical Times 2014, September 5.

8. Culliton G. Consultant vacancies 'abnormally high' Irish Medical Times 2015 February 20.

9. Cullen P. Brain drain warning over work conditions for consultants. Irish Times 2013, October 12.

10. Varley M. State must restore trust. Irish Medical Times 2014 October 1

11. McGowan $\mathrm{Y}$, Humphries $\mathrm{N}$, Burke $\mathrm{H}$, et al. Through doctors' eyes: a qualitative study of hospital doctor perspectives on their working conditions. Br J Health Psychol 2013;18:874-91.

12. Irish Medical Council. Your Training Counts Survey. 2015 ed. Dublin, Ireland, 2015.
13. Nieuwenhuijsen K, Bruinvels D, Frings-Dresen M. Psychosocial work environment and stress-related disorders, a systematic review. Occup Med (Lond) 2010;60:277-86.

14. Netterstrom B, Conrad N, Bech P, et al. The relation between work-related psychosocial factors and the development of depression. Epidemiol Rev 2008;30:118-32.

15. Tabanelli MC, Depolo M, Cooke R, et al. Available instruments for measurement of psychosocial factors in the work environment. Int Arch Occup Environ Health 2008;82:1-12.

16. Hsu C-C. The Delphi technique: making sense of consensus. Pract Assess Res Eval 2007;12.10:1-8.

17. Health and Safety Authority. Work related stress: a guide for employers. http://www.hsa.ie/eng/Publications_and_Forms/ Publications/Occupational_Health/Work_Related_Stress.pdf

18. Wallace JE, Lemaire Jb, Ghali WA. Physician wellness: a missing quality indicator. Lancet 2009;374:1714-21.

19. MacKay CJ, Cousins R, Kelly PJ, et al. 'Management Standards' and work-related stress in the UK: policy background and science. Work Stress 2004;18:91-112.

20. Karasek RA Jr. Job demands, job decision latitude, and mental strain: implications for job redesign. Adm Sci Q 1979;24: 285-308.

21. Levi L. Stressors at the workplace: theoretical models. Occup Med 2000;15:69-106.

22. Stansfeld S, Candy B. Psychosocial work environment and mental health-a meta-analytic review. Scand J Work Environ Health 2006;32:443-62.

23. Theorell T, Karasek RA. Current issues relating to psychosocial job strain and cardiovascular disease research. J Occup Health Psycho 1996;1:9-26.

24. Mark GM, AP S, editors. Stress models: a review and suggested new direction, 2008

25. Culliton G. Contract overambitious and unwieldy. Irish Medical Times 2014 August 29.

26. Kelly P. Healthcare outside the box. Irish Medical Times 2013 September 27.

27. Siegrist J. Adverse health effects of high-effort/low-reward conditions. J Occup Health Psychol 1996;1:27-41.

28. Riley GJ. Understanding the stresses and strains of being a doctor. Med J Aust 2004;181:350-3.

29. Admin. Four hospitals compliant with 48-hr week. Irish Medical Times 2015 February 52015

30. Haugh C, Doyle B, O'Flynn S. Debt crisis ahead for Irish medical students. Ir Med J 2014;107:185-6.

31. Health Service Executive. Performance Management in the HSE: Guidance Document. Secondary Performance Management in the HSE: Guidance Document 2012. http://www.hse.ie/eng/staff/ Benefits_Services/Performance_Management/Guidance Doc.pdf

32. Reason J. Human error: models and management. BMJ $2000 ; 320 \cdot 768-70$. 